\title{
Estimated Next Menstrual Period Start Date
}

National Cancer Institute

\section{Source}

National Cancer Institute. Estimated Next Menstrual Period Start Date. NCI Thesaurus.

Code C158276.

The approximate date of the first day of the next menstrual cycle. 